Jin Liu, Min Liu, Shiqing Wang, Yuxiao Li, Mingzhu Liu, Yue Wang, Laijin Tian* and Xicheng Liu*

\title{
Syntheses and crystal structures of three bis(triorganotin) benzenedicarboxylates
}

https://doi.org/10.1515/mgmc-2018-0031

Received June 14, 2018; accepted October 14, 2018; previously published online November 15, 2018

Abstract: Three bis(triorganotin) benzenedicarboxylates, $1, n-\mathrm{C}_{6} \mathrm{H}_{4}\left(\mathrm{COOSnR}_{3}\right)_{2}\left(n, \mathrm{R}=3, \mathrm{C}_{6} \mathrm{H}_{5} \mathrm{C}\left(\mathrm{CH}_{3}\right)_{2} \mathrm{CH}_{2}, \mathbf{1}\right.$; 4, $\left.\mathrm{C}_{6} \mathrm{H}_{5} \mathrm{C}\left(\mathrm{CH}_{3}\right)_{2} \mathrm{CH}_{2}, 2 ; 4, \mathrm{C}_{6} \mathrm{H}_{11}-\mathrm{c}, 3\right)$, were synthesized by the reaction of 1,3 or 1,4-benzenedicarboxylic acid with triorganotin chlorides in the solution of $\mathrm{CH}_{3} \mathrm{ONa}-\mathrm{CH}_{3} \mathrm{OH}$ and characterized by means of elemental analysis, Fouriertransform infrared spectroscopy (FT-IR), nuclear magnetic resonance (NMR) $\left({ }^{1} \mathrm{H},{ }^{13} \mathrm{C}\right.$, and $\left.{ }^{119} \mathrm{Sn}\right)$ spectra, and X-ray single-crystal diffraction. Compounds 1-3 are all di-nuclear tin complexes in which the carboxylate is monodentate and each tin atom possesses a distorted $\mathrm{SnC}_{3} \mathrm{O}$ tetrahedral geometry.

Keywords: complex; crystal structure; organotin; organotin carboxylate.

\section{Introduction}

Organotin compounds are widely used in industrial and agricultural production such as polyvinyl chloride (PVC) stabilizers, biocides, acaricides, catalysts, and surface curing agents (Davies et al., 2008). Organotin carboxylates, a class of organotin compounds, have been attracting great attention because of their structural diversity and biological properties, particularly anti-tumor activity (Tiekink, 1994; Ma et al., 2005, 2012; Davies et al., 2008; Hadjikakou and Hadjiliadis, 2009; Amir et al., 2014). Triorganotin carboxylates usually possess discrete structures and chain or macro-cyclic structures formed by the carboxylate ligand bridging two tin centers $(\mathrm{Sn}-\mathrm{O}-\mathrm{C}=\mathrm{O} \rightarrow \mathrm{Sn}$ ) (Tiekink, 1994; Chandrasekhar

\footnotetext{
*Corresponding authors: Laijin Tian, Key Laboratory of Natural Products and Pharmaceutical Intermediates, Qufu Normal University, Qufu 273165, China, e-mail: laijintian@163.com; and Xicheng Liu, Institute of Anticancer Agents Development, Qufu Normal University, Qufu 273165, China, e-mail: chemlxc@163.com Jin Liu, Min Liu, Shiqing Wang, Yuxiao Li, Mingzhu Liu and Yue Wang: Key Laboratory of Natural Products and Pharmaceutical Intermediates, Qufu Normal University, Qufu 273165, China
}

et al., 2002; Davies et al., 2008). A large variety of triorganotin carboxylates from aliphatic and aromatic carboxylic acids were synthesized and structurally characterized by X-ray single diffractions (Tiekink, 1994; Chandrasekhar et al., 2002; Davies et al., 2008; Shang et al., 2011; Ma et al., 2012; Amir et al., 2014, Zhang et al., 2014). Recently, we also reported the syntheses and crystal structures of some triorganotin carboxylates (Tian et al., 2013, 2015; Dong et al., 2014; Zhang et al., 2016; Yao et al., 2017). In order to continue to expand the structural chemistry of trioganotin carboxylates and further explore the effects of alkyls bound to tin atom on the molecular structures, we select the bulky alkyltin chlorides as organotin precursor and synthesize three bis(triorganotin) benzenedicarboxylates, $1, n-\mathrm{C}_{6} \mathrm{H}_{4}\left(\mathrm{COOSnR}_{3}\right)_{2}\left(n, \mathrm{R}=3, \mathrm{C}_{6} \mathrm{H}_{5} \mathrm{C}\left(\mathrm{CH}_{3}\right)_{2} \mathrm{CH}_{2}, \mathbf{1}\right.$; 4, $\left.\mathrm{C}_{6} \mathrm{H}_{5} \mathrm{C}\left(\mathrm{CH}_{3}\right)_{2} \mathrm{CH}_{2}, 2 ; 4, \mathrm{C}_{6} \mathrm{H}_{11}-\mathrm{C}, 3\right)$, and determine their crystal structures.

\section{Results and discussion}

\section{Synthesis}

Compounds 1-3 were prepared by the reaction of 1,3- or 1,4-benzenedicarboxylic acid with triorganotin chlorides in the molar ratio $1: 2$ in the solution of $\mathrm{CH}_{3} \mathrm{ONa}-\mathrm{CH}_{3} \mathrm{OH}$, which can be represented by the following equation:

$$
\begin{aligned}
& 1, n-\mathrm{C}_{6} \mathrm{H}_{4}(\mathrm{COOH})_{2}+2 \mathrm{CH}_{3} \mathrm{ONa}+2 \mathrm{R}_{3} \mathrm{SnCl} \rightarrow \\
& 1, n-\mathrm{C}_{6} \mathrm{H}_{4}\left(\mathrm{COOSnR}_{3}\right)_{2}+2 \mathrm{CH}_{3} \mathrm{OH}+2 \mathrm{NaCl} \\
& \left.n, \mathrm{R}=3, \mathrm{C}_{6} \mathrm{H}_{5} \mathrm{C}_{(} \mathrm{CH}_{3}\right)_{2} \mathrm{CH}_{2},(\mathbf{1}) ; 4, \mathrm{C}_{6} \mathrm{H}_{5} \mathrm{C}\left(\mathrm{CH}_{3}\right)_{2} \\
& \mathrm{CH}_{2},(\mathbf{2}) ; 4, \mathrm{C}_{6} \mathrm{H}_{11}-\mathrm{C},(\mathbf{3})
\end{aligned}
$$

These compounds are all colorless crystals and are soluble in common organic solvents such as methanol, acetone, benzene, and chloroform.

\section{Spectroscopic analysis}

The infrared spectra of the complexes do not show a broad band at $-3300 \mathrm{~cm}^{-1}$ assigned to $\mathrm{v}(\mathrm{O}-\mathrm{H})$, indicting 
the deprotonation of the carboxylic acids. The appearance of a band at $\sim 490 \mathrm{~cm}^{-1}$ assignable to the $\mathrm{Sn}-\mathrm{O}$ stretching vibration confirms the formation of a $\mathrm{Sn}-\mathrm{O}$ bond (Xie et al., 1989; Ma et al., 2005; Zhang et al., 2014). The strong bands at $\sim 1630 \mathrm{~cm}^{-1}$ and $\sim 1330 \mathrm{~cm}^{-1}$ are assigned to the asymmetrical stretching vibration $\left[v_{\mathrm{as}}(\mathrm{COO})\right]$ and symmetrical stretching vibration $\left[v_{s}(\mathrm{COO})\right]$ of the carboxylates, respectively. In organotin carboxylates, infrared (IR) spectroscopy can provide useful information concerning the coordination mode of the carboxylate group. Generally, the difference between the $v_{a s}(\mathrm{COO})$ and $v_{s}(\mathrm{COO})$ bands, $\Delta v(\mathrm{COO})$, of the bidentate carboxylate group is smaller than $200 \mathrm{~cm}^{-1}$, while the unidentate carboxylate is larger than $200 \mathrm{~cm}^{-1}$ (Deacon and Phillips, 1980). The magnitudes (283-318 $\left.\mathrm{cm}^{-1}\right)$ of $\Delta v(\mathrm{COO})$ in 1-3 indicate that the carboxylate groups are coordinated to tin atoms in a monodentate mode in the solid state, which is in agreement with the X-ray diffraction analyses of $\mathbf{1 - 3}$ below.

In the ${ }^{1} \mathrm{H}$ NMR spectra of the compounds, the proton resonances of carboxylic acids are not observed, which further confirm the replacement of the carboxylic acid protons. In 1, the proton signals of 1,3-benzenedicarboxylate ligand appear at 7.53, 8.32, and $9.03 \mathrm{ppm}$, and in 2 and 3, a single peak at $8.20 \mathrm{ppm}$ is assigned to the proton resonances of 1,4-benzenedicarboxylate. The proton resonances of alkyl on the tin atom lie in the normal ranges.

The ${ }^{13} \mathrm{C}$ chemical shifts of the carboxyl in 1-3 appear at $173 \mathrm{ppm}$. The resonance signals of the 2-methylpropyl group carbons in $\mathbf{1}$ and $\mathbf{2}$ are in the range $32-38 \mathrm{ppm}$, and the resonances of cyclohexyl in $\mathbf{3}$ appear in the range
26-35 ppm. The spin-spin coupling constants, ${ }^{1} J\left({ }^{(19} \mathrm{Sn}-{ }^{13} \mathrm{C}\right)$, are in the range of $326-342 \mathrm{~Hz}$, which are characteristic of the four-coordinate tin atoms (Nadvornik et al., 1984; Tian et al., 2015) . The ${ }^{119} \mathrm{Sn}$ chemical shifts primarily depend on the coordination number and the nature of the donor atom directly bound to the central tin atom (Davies et al., 2008). The complexes $\mathbf{1 - 3}$ exhibit a single ${ }^{119} \mathrm{Sn}$ resonance at 105.1, 104.8, and $16.3 \mathrm{ppm}$, respectively, which fall well within the range proposed for the four-coordinate tin centers (Nadvornik et al., 1984; Holecek et al., 1986; Willem, et al., 1998). Thus, the tin atoms in the complexes have four-coordinate environments in the $\mathrm{CDCl}_{3}$ solution.

\section{Structure analysis}

The molecular structures of 1-3 are shown in Figures 1-3. The selected bond lengths and bond angles are listed in Table 1. Compound 1 crystallizes in the monoclinic space group $P 2_{1} / c$ and is a di-nuclear tin complex in which each tin atom is a four coordinate and possesses a distorted $\mathrm{SnC}_{3} \mathrm{O}$ tetrahedral geometry with the bond angles of $94.89(11)^{\circ}-118.64(12)^{\circ}$ (Figure 1). The four coordination atoms of the tin atom come from the three carbon atoms of the 2-phenyl-2-methylpropyl groups and a carboxylate oxygen atom, which is monodentate to the tin atom. The tetrahedral nature of tris(2-methyl-2-phenylpropyl)tin carboxylates arises from the crowding of the three organic groups covalently bonded to the tin atom, and such compounds are an exception to the observation that trialkyltin

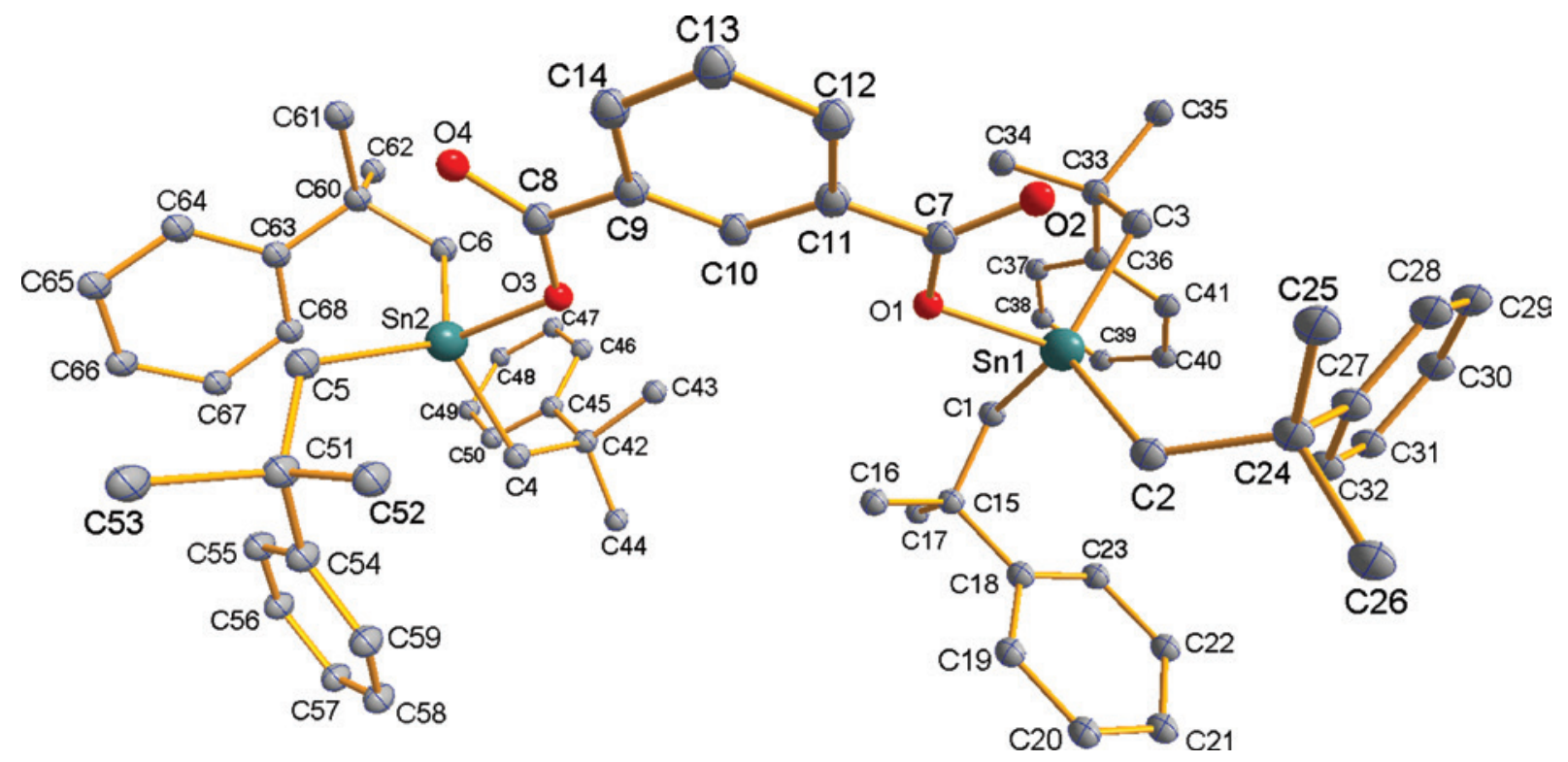

Figure 1: The molecular structure of 1.

Displacement ellipsoids are drawn at the $30 \%$ probability level; hydrogen atoms are omitted for clarity. 


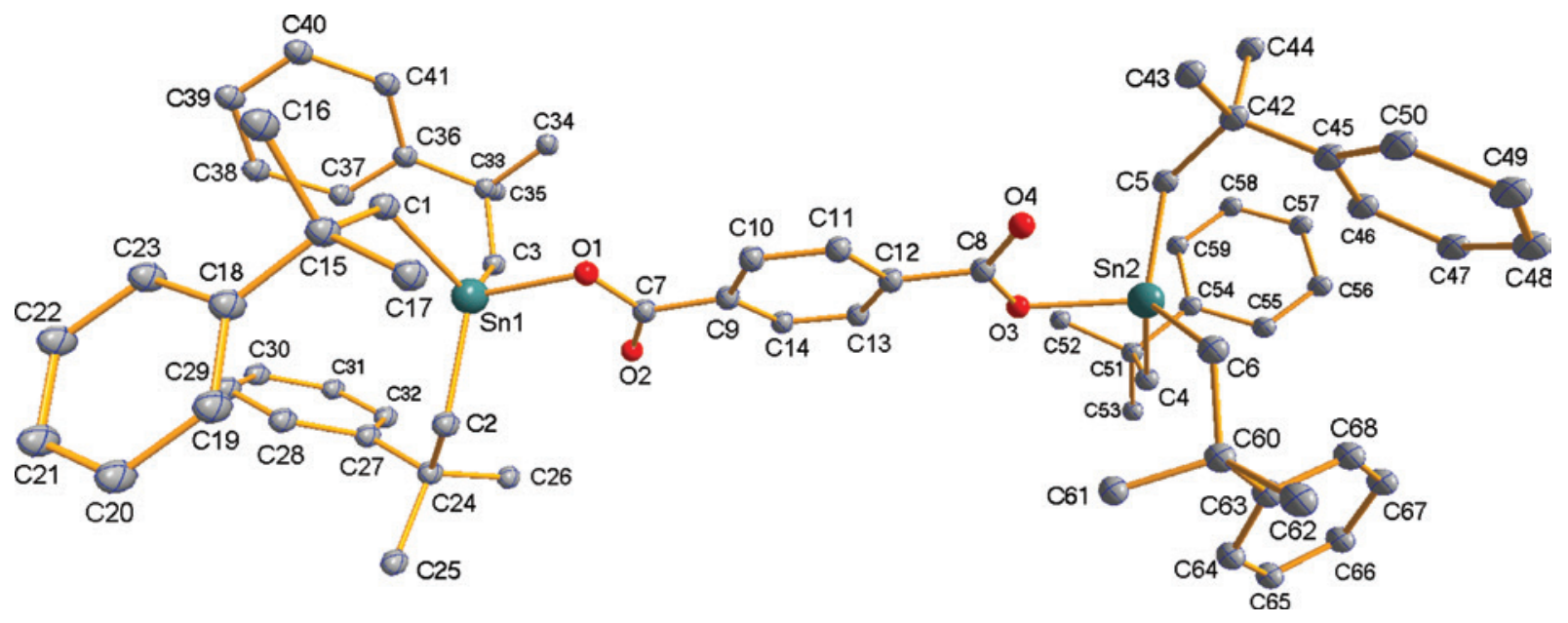

Figure 2: The molecular structure of 2.

Displacement ellipsoids are drawn at the $30 \%$ probability level; hydrogen atoms are omitted for clarity.

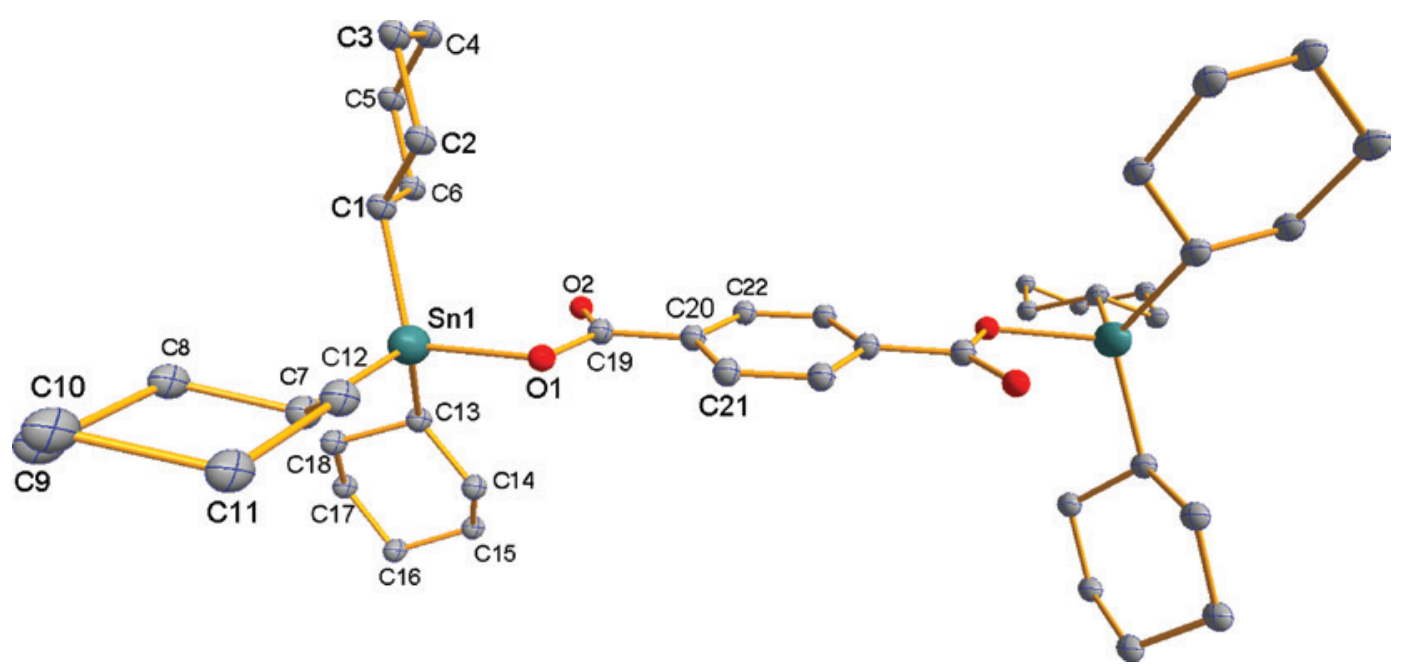

Figure 3: The molecular structure of 3.

Displacement ellipsoids are drawn at the $30 \%$ probability level; hydrogen atoms are omitted for clarity. Unlabeled atoms are related to labeled atoms by $-x+1 / 2,-y+3 / 2,-z+1$.

carboxylates auto-associate into polymers through carboxylate bridging (Tiekink, 1994; Chandrasekhar et al., 2002). The four bond lengths to $S n$ (Table 1) are similar to those found in other reported tris(2-methyl-2-phenylpropyl)tin carboxylates, such as 3,5-di-tert-butyl-4-hydroxybenzoate (Ding et al., 2012), and 2,6-pyridinedicarboxylate (Wang et al., 2014). The $\mathrm{Sn}(1) \cdots \mathrm{O}(2)$ and $\mathrm{Sn}(2) \cdots \mathrm{O}(4)$ separations of 2.896(2) and 3.030(2) $\AA$ are not indicative of a significant interaction between these atoms. The major stereochemical roles of atoms $\mathrm{O}(2)$ and $\mathrm{O}(4)$ are to distort the tetrahedral geometry by opening up the bond angels $\mathrm{C}(2)-\mathrm{Sn}(1)-\mathrm{C}(3)$ and $\mathrm{C}(5)-\mathrm{Sn}(2)-\mathrm{C}(6)$ to $118.64(12)^{\circ}$ and $118.63(12)^{\circ}$, and reducing the $\mathrm{O}(1)-\mathrm{Sn}(1)-\mathrm{C}(1)$ and
$\mathrm{O}(3)-\mathrm{Sn}(2)-\mathrm{C}(4)$ to $96.04(12)^{\circ}$ and $94.89(11)^{\circ}$, respectively. The monodentate mode of coordination of the carboxylate group is also reflected in the two disparate $\mathrm{C}-\mathrm{O}$ bond lengths (C(7)-O(1) of 1.289(4) $\AA$ and $\mathrm{C}(7)-\mathrm{O}(2)$ of 1.222(4) $\AA$, and C(8)-O(3) of 1.297(4) $\AA$ and C(8)-O(4) of 1.216(4) $\mathrm{A})$. The carboxylate groups and phenyl ring from the 1,3-benzenedicarboxylate ligand are not in the same plane, and the dihedral angles between the phenyl ring and each of the two carboxylate planes are $9.80(1)^{\circ}$ and $19.82(1)^{\circ}$, respectively, and the dihedral angle between the two carboxylate planes is $14.43(2)^{\circ}$.

Tetrahedral coordination of the tin atom is also observed in compound 2 (Figure 2), the two tin atoms 
Table 1: Selected bond lengths $(\AA)$ and angles $\left(^{\circ}\right)$ for 1-3.

\begin{tabular}{|c|c|c|c|c|c|}
\hline 1 & & & & & \\
\hline $\operatorname{Sn}(1)-0(1)$ & $2.092(2)$ & $\operatorname{Sn}(2)-0(3)$ & $2.076(2)$ & $C(7)-O(1)$ & $1.289(4)$ \\
\hline $\operatorname{Sn}(1) \cdots O(2)$ & $2.896(2)$ & $\operatorname{Sn}(2) \cdots O(4)$ & $3.030(2)$ & $C(7)-O(2)$ & $1.222(4)$ \\
\hline $\operatorname{Sn}(1)-C(1)$ & $2.151(3)$ & $\operatorname{Sn}(2)-C(4)$ & $2.147(3)$ & $C(8)-O(3)$ & $1.297(4)$ \\
\hline$S n(1)-C(2)$ & $2.141(3)$ & $\operatorname{Sn}(2)-C(5)$ & $2.142(3)$ & $C(8)-0(4)$ & $1.216(4)$ \\
\hline$S n(1)-C(3)$ & $2.139(3)$ & $\operatorname{Sn}(2)-C(6)$ & $2.145(3)$ & & \\
\hline$O(1)-S n(1)-C(1)$ & $96.04(12)$ & $C(3)-S n(1)-C(1)$ & $113.38(13)$ & $C(5)-S n(2)-C(6)$ & $118.63(12)$ \\
\hline$O(1)-S n(1)-C(2)$ & 103.13(11) & $C(2)-S n(1)-C(1)$ & $115.08(13)$ & $O(3)-S n(2)-C(4)$ & $94.89(11)$ \\
\hline$O(1)-S n(1)-C(3)$ & $106.82(12)$ & $O(3)-S n(2)-C(5)$ & $105.76(11)$ & $C(5)-S n(2)-C(4)$ & $115.24(12)$ \\
\hline$C(3)-S n(1)-C(2)$ & $118.64(12)$ & $O(3)-S n(2)-C(6)$ & $105.27(12)$ & $C(6)-S n(2)-C(4)$ & $113.18(13)$ \\
\hline 2 & & & & & \\
\hline $\operatorname{Sn}(1)-0(1)$ & $2.0882(17)$ & $\operatorname{Sn}(2)-0(3)$ & $2.0837(18)$ & $C(7)-O(1)$ & $1.302(3)$ \\
\hline $\mathrm{Sn}(1) \cdots O(2)$ & $2.967(2)$ & $\operatorname{Sn}(2) \cdots O(4)$ & $3.000(2)$ & $C(7)-O(2)$ & $1.219(3)$ \\
\hline $\operatorname{Sn}(1)-C(1)$ & $2.149(3)$ & $\operatorname{Sn}(2)-C(4)$ & $2.155(3)$ & $C(8)-O(3)$ & $1.294(3)$ \\
\hline $\mathrm{Sn}(1)-C(2)$ & $2.147(3)$ & $\operatorname{Sn}(2)-C(5)$ & $2.145(3)$ & $C(8)-0(4)$ & $1.216(3)$ \\
\hline $\operatorname{Sn}(1)-C(3)$ & 2.151(3) & $\operatorname{Sn}(2)-C(6)$ & $2.145(3)$ & & \\
\hline$O(1)-S n(1)-C(1)$ & $95.45(10)$ & $C(2)-S n(1)-C(3)$ & $119.45(11)$ & $C(6)-S n(2)-C(5)$ & $118.74(12)$ \\
\hline$O(1)-S n(1)-C(2)$ & $102.88(10)$ & $C(1)-S n(1)-C(3)$ & $116.68(11)$ & $O(3)-S n(2)-C(4)$ & $95.28(10)$ \\
\hline$O(1)-S n(1)-C(3)$ & $104.24(10)$ & $O(3)-S n(2)-C(6)$ & $105.34(10)$ & $C(6)-S n(2)-C(4)$ & $113.17(11)$ \\
\hline$C(2)-S n(1)-C(1)$ & $113.23(11)$ & $O(3)-S n(2)-C(5)$ & 103.71(11) & $C(5)-S n(2)-C(4)$ & $116.34(12)$ \\
\hline $3 \cdot \mathrm{C}_{6} \mathrm{H}_{6}$ & & & & & \\
\hline $\mathrm{Sn}(1)-\mathrm{O}(1)$ & $2.070(2)$ & $\mathrm{Sn}(1)-C(7)$ & $2.162(4)$ & $C(19)-O(1)$ & $1.302(4)$ \\
\hline $\mathrm{Sn}(1) \cdots \mathrm{O}(2)$ & $2.899(2)$ & $\operatorname{Sn}(1)-C(13)$ & $2.149(4)$ & $C(19)-O(2)$ & $1.211(4)$ \\
\hline $\operatorname{Sn}(1)-C(1)$ & $2.145(4)$ & & & & \\
\hline$O(1)-S n(1)-C(1)$ & $108.29(13)$ & $O(1)-S n(1)-C(13)$ & $106.29(14)$ & $C(1)-S n(1)-C(13)$ & $118.95(16)$ \\
\hline$O(1)-S n(1)-C(7)$ & $95.49(13)$ & $C(1)-S n(1)-C(7)$ & $112.32(16)$ & $C(13)-S n(1)-C(7)$ & $112.54(16)$ \\
\hline
\end{tabular}

$\operatorname{Sn}(1)$ and $\operatorname{Sn}(2)$ are bridged by the two carboxylates $\mathrm{O}(1)$ and $\mathrm{O}(3)$ of the 1,4-benzenedicarboxylate ligand. The distances of Sn-O (2.0882(17) and 2.0837(18) Å) and Sn-C (2.145(3)-2.155(3) ^) are comparable to those observed in 1 (Table 1) and tris(2-methyl-2-phenylpropyl)tin 3,5-ditert-butyl-4-hydroxybenzoate (Sn-O 2.074(2) ^ and Sn-C 2.142(3)-2.158(3) Å) (Ding et al., 2012).

Compound 3 (Figure 3) crystallizes in a monoclinic system with the space group $C 2 / c$, and an asymmetric unit contains half a molecule of $\mathbf{3}$ and half a benzene molecule. The two tin atoms are equivalent (symmetry code: $-x+1 / 2,-y+3 / 2,-z+1)$ due to the presence of an inversion center in the molecule, and the coordination geometry of the tin atom is a distorted tetrahedron with the bond angles of $95.49(13)^{\circ}-118.95(16)^{\circ}$. The covalent $\operatorname{Sn}(1)-$ $\mathrm{O}(1)$ distance $(2.070(2) \AA)$ and the $\mathrm{Sn}(1)$. . O O(2) separation (2.899(2) A) are slightly shorter than those of 2 (2.0882(17) and 3.000(2) $\AA$ ), which may arise from more crowding of the three 2-methyl-2-phenylpropyl groups compared with the cyclohexyl groups. The carboxylate group and the phenyl ring are almost in the same plane, and the dihedral angle between the phenyl ring and the carboxylate plane is only 1.36(34) $)^{\circ}$. The structural features of $\mathbf{3}$ are in agreement with those reported for tricyclohexyltin carboxylates such as tricyclohexyltin 3,5-di-tert-butyl-4-hydroxybenzoate
(Ding et al., 2012), ferrocenecarboxylate (Dong et al., 2014), phenoxyacetate (Zhang et al., 2015), and salicylate (Zhang et al., 2016).

In summary, three bis(triorganotin) benzenedicarboxylates 1-3 were synthesized and characterized. They are all di-nuclear tin complexes in which the benzenedicarboxylate ligand binds the two tin atoms in a monodentate coordination mode via its carboxylate groups, and each tin atom possesses a distorted $\mathrm{SnC}_{3} \mathrm{O}$ tetrahedral geometry.

\section{Experimental}

\section{General}

Tris(2-phenyl-2-methylpropyl)tin chloride was prepared according to literature procedure (Reichle, 1966). All other chemicals were of reagent grade and were used without further purification (Sinopharm Chemical Reagent Company Limited, Shanghai, China). Carbon and hydrogen analyses were determined using a Perkin Elmer 2400 Series II elemental analyzer (Perkin Elmer, Waltham, MA, USA). IR spectra were recorded on a Nicolet 470 FT-IR spectrophotometer using $\mathrm{KBr}$ discs in the range $4000-400 \mathrm{~cm}^{-1}$ (Thermo Nicolet Corporation, Madison, WI, USA). ${ }^{1} \mathrm{H}$ NMR spectral data were collected using a Bruker Avance $\mathrm{HD} 500$ NMR spectrometer with $\mathrm{CDCl}_{3}$ as the solvent and tetramethylsilane as the internal standard (Bruker BioSpin, Switzerland). 
The ${ }^{119} \mathrm{Sn}$ NMR spectra were recorded in $\mathrm{CDCl}_{3}$ on a Varian Mercury Vx300 spectrometer using $\mathrm{Me}_{4} \mathrm{Sn}$ external reference (Varian Corporation, Palo Alto, CA, USA).

\section{Synthesis of bis(triorgano)tin benzenedicarboxylates}

Bis[tris(2-phenyl-2-methylpropyl)tin] 1,3-benzenedicarboxylate (1): The compounds 1,3-benzenedicarboxylic acid $(0.166 \mathrm{~g}, 1 \mathrm{mmol})$ and sodium methanoxide $(0.108 \mathrm{~g}, 2 \mathrm{mmol})$ were added to $40 \mathrm{~mL}$ of methanol. The mixture was stirred for $10 \mathrm{~min}$, and then, tris(2-methyl-2-phenylpropyl)tin chloride (1.108 g, $2 \mathrm{mmol}$ ) was added to the mixture, continuing the reaction for $3 \mathrm{~h}$ under reflux. The solution was cool to room temperature and filtered. The filtrate was evaporated under reduced pressure by a rotary evaporator. The resulting white solid was recrystallized from methanol-chloroform (1:1, V/V) and dried in a vacuum dryer for $12 \mathrm{~h}$. Yield $0.923 \mathrm{~g}(77 \%)$, m.p. $104-106^{\circ} \mathrm{C}$. Anal. Found: C, 67.74; H, 6.59. Calcd for $\mathrm{C}_{68} \mathrm{H}_{82} \mathrm{O}_{4} \mathrm{Sn}_{2}$ : C, 68.02; H, 6.88\%. Selected IR (KBr) cm${ }^{-1}: 1644\left[v(\mathrm{COO})_{a \mathrm{a}}\right], 1326[v(\mathrm{COO})], \Delta v(\mathrm{COO})=318$, $493[v(\mathrm{Sn}-\mathrm{O})] .{ }^{1} \mathrm{H}$ NMR $\left(\mathrm{CDCl}_{3}\right) \delta: 1.25\left(\mathrm{~s}, 36 \mathrm{H}, 12 \mathrm{CH}_{3}\right), 1.29$ (s, J( ${ }^{119} \mathrm{Sn}-$ $\left.\left.{ }^{1} \mathrm{H}\right)=50 \mathrm{~Hz}, 12 \mathrm{H}, 6 \mathrm{CH}_{2}\right), 7.13(\mathrm{~d}, J=7.5 \mathrm{~Hz}, 12 \mathrm{H}, o-\mathrm{H}$ of phenyl), $7.21(\mathrm{t}$, $J=7.5 \mathrm{~Hz}, 6 \mathrm{H}, p$ - $\mathrm{H}$ of phenyl), 7.29 (t, $J=7.5 \mathrm{~Hz}, 12 \mathrm{H}, m-\mathrm{H}$ of phenyl), 7.53 (t, $J=7.5 \mathrm{~Hz}, 1 \mathrm{H}, \mathrm{H}-5), 8.32$ (dd, $J=1.5,7.5 \mathrm{~Hz}, 2 \mathrm{H}, \mathrm{H}-4+\mathrm{H}-6$ ), 9.03 (t, $J=1.5 \mathrm{~Hz}, 1 \mathrm{H}, \mathrm{H}-2)$ ppm. ${ }^{13} \mathrm{C}$ NMR ( $\left.\mathrm{CDCl}_{3}\right) \delta: 173.27$ (COOSn), 150.95 (i-C of phenyl), 135.44 (C-4,6), 132.66 (C-2), 130.43 (C-1,3), 128.67 (C-5), 128.52 ( $m$-C of phenyl), 125.90 ( $p$-C of phenyl), 125.33 (o-C of phenyl), $37.92\left({ }^{1}\left({ }^{119} \mathrm{Sn}^{-13} \mathrm{C}\right)=342 \mathrm{~Hz}, \mathrm{C}-\alpha\right), 37.71\left({ }^{2} J\left({ }^{(19} \mathrm{Sn}{ }^{-13} \mathrm{C}\right)=20 \mathrm{~Hz}, \mathrm{C}-\beta\right), 33.15$ $\left({ }^{3} J\left({ }^{119} \mathrm{Sn}^{-13} \mathrm{C}\right)=46 \mathrm{~Hz}, \mathrm{C}-\gamma\right) \mathrm{ppm} .{ }^{119} \mathrm{Sn}$ NMR $\left(\mathrm{CDCl}_{3}\right) \delta: 105.1 \mathrm{ppm}$.

Bis[tris(2-phenyl-2-methylpropyl)tin] 1,4-benzenedicarboxylate (2): Compound 2 was prepared in the same way as $\mathbf{1}$, by adding tris(2-methyl-2-phenylpropyl)tin chloride (1.108 g, 2 mmol) to 1,4-benzenedicarboxylic acid ( $0.166 \mathrm{~g}, 1 \mathrm{mmol})$. The colorless crystals (m.p. $121^{\circ}-122^{\circ} \mathrm{C}$ ) were obtained in a yield of $0.984 \mathrm{~g}(82 \%)$. Anal. Found: C, 68.31; H, 6.72. Calcd for $\mathrm{C}_{68} \mathrm{H}_{82} \mathrm{O}_{4} \mathrm{Sn}_{2}: \mathrm{C}, 68.02 ; \mathrm{H}, 6.88 \%$. Selected IR $(\mathrm{KBr}) \mathrm{cm}^{-1}: 1645\left[\mathrm{v}(\mathrm{COO})_{\mathrm{as}}\right], 1332\left[\mathrm{v}(\mathrm{COO})_{\mathrm{s}}\right], \Delta v(\mathrm{COO})=313,491$ [v(Sn-O)]. ${ }^{1} \mathrm{H} \mathrm{NMR}\left(\mathrm{CDCl}_{3}\right) \delta: 1.24$ (s, 36H, $\left.12 \mathrm{CH}_{3}\right), 1.26\left(\mathrm{~s}, 12 \mathrm{H}, 6 \mathrm{CH}_{2}\right)$, 7.12 (d, $J=7.5 \mathrm{~Hz}, 12 \mathrm{H}, o-\mathrm{H}$ in phenyl), 7.20 (t, $J=7.5 \mathrm{~Hz}, 6 \mathrm{H}, p-\mathrm{H}$ of phenyl), 7.28 (t, $J=7.5 \mathrm{~Hz}, 12 \mathrm{H}, m-\mathrm{H}$ of phenyl), 8.20 (s, 4H, Ar-H) ppm. ${ }^{13} \mathrm{C}$ NMR ( $\mathrm{CDCl}_{3}$ ) $\delta: 173.22$ (COOSn), 150.64 (i-C of phenyl), 136.33 (C-1,4), 129.75 (C-2,3,5,6), 128.51 ( $m$-C of phenyl), 126.06 ( $p$-C of phenyl), 125.26 (o-C of phenyl), $37.99\left({ }^{1} J\left({ }^{119} \mathrm{Sn}^{-13} \mathrm{C}\right)=338 \mathrm{~Hz}, \mathrm{C}-\alpha\right), 37.74$ $\left({ }^{2}\left({ }^{119} \mathrm{Sn}-{ }^{13} \mathrm{C}\right)=20 \mathrm{~Hz}, \mathrm{C}-\beta\right), 32.88\left({ }^{3}\left({ }^{1{ }^{119}} \mathrm{Sn}^{-13} \mathrm{C}\right)=45 \mathrm{~Hz}, \mathrm{C}-\gamma\right) \mathrm{ppm} .{ }^{119} \mathrm{Sn}$ $\mathrm{NMR}\left(\mathrm{CDCl}_{3}\right) \delta: 104.8 \mathrm{ppm}$.

Bis(tricyclohexyltin) 1,4-benzenedicarboxylate (3): Compound 3 was prepared in the same way as $\mathbf{1}$, by adding tricyclohexyltin chloride ( $0.808 \mathrm{~g}, 2 \mathrm{mmol})$ to 1,4-benzenedicarboxylic acid (0.166 g, $1 \mathrm{mmol}$ ). The colorless crystals (m.p. $138^{\circ}-139^{\circ} \mathrm{C}$ ) were obtained in a yield of $0.657 \mathrm{~g}(73 \%)$. Anal. Found: C, 58.35; H, 7.66. Calcd for $\mathrm{C}_{44} \mathrm{H}_{70} \mathrm{O}_{4} \mathrm{Sn}_{2}: \mathrm{C}, 58.69 ; \mathrm{H}, 7.84 \%$. Selected IR $(\mathrm{KBr}) \mathrm{cm}^{-1}: 1624$ [v(COO) $)_{\text {as }}$, $\left.1341[v(\mathrm{COO}))_{\mathrm{s}}\right], \Delta v(\mathrm{COO})=283,489[v(\mathrm{Sn}-0)] .{ }^{1} \mathrm{H} \mathrm{NMR}\left(\mathrm{CDCl}_{3}\right) \delta: 2.04-$ $1.30\left(\mathrm{~m}, 66 \mathrm{H}, 6 \mathrm{C}_{6} \mathrm{H}_{11}\right), 8.22(\mathrm{~s}, 4 \mathrm{H}, \mathrm{Ar}-\mathrm{H}) \mathrm{ppm} .{ }^{13} \mathrm{C} \mathrm{NMR}\left(\mathrm{CDCl}_{3}\right) \delta: 173.62$ (COOSn), $136.25(\mathrm{C}-1,4), 129.62(\mathrm{C}-2,3,5,6), 34.56\left({ }^{1}\left({ }^{119} \mathrm{Sn}^{-13} \mathrm{C}\right)=326 \mathrm{~Hz}\right.$, $\mathrm{C}-\alpha), 31.09\left({ }^{2} J\left({ }^{119} \mathrm{Sn}-{ }^{13} \mathrm{C}\right)=16 \mathrm{~Hz}, \mathrm{C}-\beta\right), 28.91\left({ }^{3} J\left({ }^{119} \mathrm{Sn}-{ }^{13} \mathrm{C}\right)=65 \mathrm{~Hz}, \mathrm{C}-\gamma\right)$, 26.85 (C- $\delta$ ) ppm. ${ }^{119} \mathrm{Sn} \mathrm{NMR}\left(\mathrm{CDCl}_{3}\right) \delta: 16.3 \mathrm{ppm}$.

\section{X-ray crystallography}

The colorless single crystals suitable for X-ray measurements were obtained from chloroform-methanol (1:1, V/V) for $\mathbf{1}$ and $\mathbf{2}$ and

Table 2: Crystallographic and refinement data of 1-3.

\begin{tabular}{|c|c|c|c|}
\hline Compound & 1 & 2 & $3 \cdot \mathrm{C}_{6} \mathrm{H}_{6}$ \\
\hline Empirical formula & $\mathrm{C}_{68} \mathrm{H}_{82} \mathrm{O}_{4} \mathrm{Sn}_{2}$ & $\mathrm{C}_{68} \mathrm{H}_{82} \mathrm{O}_{4} \mathrm{Sn}_{2}$ & $\mathrm{C}_{50} \mathrm{H}_{76} \mathrm{O}_{4} \mathrm{Sn}_{2}$ \\
\hline Formula weight & 1200.72 & 1200.72 & 978.49 \\
\hline Crystal system & Monoclinic & Monoclinic & Monoclinic \\
\hline Space group & $P 2_{1} / \mathrm{C}$ & $P 2_{1} / \mathrm{C}$ & $\mathrm{C} 2 / \mathrm{c}$ \\
\hline$a / \AA$ & $18.686(3)$ & $18.6240(13)$ & $30.305(4)$ \\
\hline$b / \AA$ & $17.953(3)$ & $18.3702(13)$ & $9.7751(13)$ \\
\hline$c / \AA$ & 19.098(3) & 18.9964(13) & $21.403(3)$ \\
\hline$\beta /\left(^{\circ}\right)$ & $105.439(2)$ & $106.430(1)$ & $128.362(1)$ \\
\hline Volume $/ \AA^{3}$ & 6175.9(17) & $6233.8(8)$ & 4971.5(12) \\
\hline$Z$ & 4 & 4 & 4 \\
\hline$D_{c} /\left(\mathrm{g} \cdot \mathrm{cm}^{-3}\right)$ & 1.291 & 1.279 & 1.307 \\
\hline$\mu / \mathrm{mm}^{-1}$ & 0.854 & 0.846 & 1.044 \\
\hline$F(000)$ & 2488 & 2488 & 2032 \\
\hline Crystal size/mm & $0.26 \times 0.20 \times 0.05$ & $0.20 \times 0.16 \times 0.10$ & $0.56 \times 0.50 \times 0.44$ \\
\hline$\theta$ range $/\left(^{\circ}\right)$ & $1.58-26.00$ & $1.14-26.00$ & $1.91-26.00$ \\
\hline Tot. reflections & 47023 & 48496 & 18612 \\
\hline Uniq. reflections, $R_{\text {int }}$ & $12097,0.0463$ & $12246,0.0327$ & $4885,0.0318$ \\
\hline Reflections with $I>2 \sigma(I)$ & 9046 & 10317 & 4036 \\
\hline GOF on $F^{2}$ & 1.008 & 1.040 & 1.058 \\
\hline$R$ indices $[I>2 \sigma(I)]$ & $R=0.0394, w R=0.0837$ & $R=0.0374, w R=0.0859$ & $R=0.0380, w R=0.0944$ \\
\hline$R$ indices (all data) & $R=0.0609, w R=0.0919$ & $R=0.0463, w R=0.0902$ & $R=0.0474, w R=0.1061$ \\
\hline$\Delta \rho_{\min }, \Delta \rho_{\max } /\left(\mathrm{e} \cdot \AA^{-3}\right)$ & $-0.292,0.558$ & $-0.286,0.759$ & $-0.565,0.901$ \\
\hline
\end{tabular}


benzene for $\mathbf{3}$ by slow evaporation at room temperature. Diffractions measurements were performed on a Bruker Smart Apex imagingplate area detector fitted with graphite monochromatized Mo-K $\alpha$ radiation $(0.71073 \AA)$ using the $\varphi$ and $\omega$ scan technique. The structures were solved by direct methods and refined by a full-matrix least squares procedure based on $F^{2}$ using SHELXL-97 (Sheldrick, 2008). The non-hydrogen atoms were refined anisotropically, and hydrogen atoms were placed at calculated positions. Crystal data, collection procedures, and refinement results are summarized in Table 2. Crystallographic data were deposited with the Cambridge Crystallographic Data Centre as supplementary publication numbers CCDC 1847424-1847426.

Acknowledgments: This work was supported by the Undergraduate Innovation Project of Qufu Normal University (201710446040), the Experimental Teaching Reform Project of Qufu Normal University (sj201401), and Shandong Provincial Natural Science Foundation, China (ZR2013BM007).

\section{References}

Amir, M. K.; Khan, S.; Rehman, Z.; Shah, A.; Butler, I. S. Anticancer activity of organotin(IV) carboxylates. Inorg. Chim. Acta 2014, 423, 14-25.

Chandrasekhar, V.; Nagendran, S.; Baskar, V. Organotin assemblies containing Sn-O bonds. Coord. Chem. Rev. 2002, 235, 1-52.

Davies, A. G.; Gielen, M.; Pannell, K. H.; Tiekink, E. R. T. Tin Chemistry: Fundamentals, Frontiers, and Applications; John Wiley \& Sons, Chichester: U.K., 2008.

Deacon, G. B.; Phillips, R. J. Relationships between the carbonoxygen stretching frequencies of carboxylato complexes and the type of carboxylate coordination. Coord. Chem. Rev. 1980, 33, 227-250.

Ding, W.; Liu, Z.; Tian, L.; Quan, X. Synthesis, characterization and in vitro cytotoxicity of triorganotin 3,5-di-tert-butyl-4-hydroxybenzoates. Synth. React. Inorg. Met-Org. Nano-Met Chem. 2012, 42, 82-87.

Dong, Y.; Yu, Y.; Tian, L. Synthesis, structural characterization and antibacterial activity of triorganotin ferrocenecarboxylates. Main Group Met. Chem. 2014, 37, 91-95.

Hadjikakou, S. K.; Hadjiliadis, N. Antiproliferative and anti-tumor activity of organotin compounds. Coord. Chem. Rev. 2009, 253, 235-249.

Holecek, J.; Nadvornik, M.; Handlir, K.; Lycka, A. ${ }^{13} \mathrm{C}$ and ${ }^{119}$ Sn NMR spectra of di-n-butyltin(IV) compounds. J. Organomet. Chem. 1986, 315, 299-308.

Ma, C.; Han, Y.; Zhang, R.; Wang, D. Self-assembled triorganotin(IV) moieties with 1,3,5-benzenetricarboxylic acid: syntheses and crystal structures of monomeric, helical, and network triorganotin(IV) complexes. Eur. J. Inorg. Chem. 2005, 3024-3033.
Ma, C.; Zhang, S.; Zhang, R. Syntheses and structural characterization of organotin(IV) complexes derived from the self-assembly of 2,4-diethylglutaric acid, phthalyl-glutamic acid and trialkyltin salts. J. Organomet. Chem. 2012, 701, 43-50.

Nadvornik, M.; Holecek, J.; Handlir, K.; Lycka, A. The ${ }^{13} \mathrm{C}$ and ${ }^{119} \mathrm{Sn}$ NMR spectra of some four- and five-coordinate tri-n-butyltin compounds. J. Organomet. Chem. 1984, 275, 43-51.

Reichle, W. T. Tetraneophyltin and its derivatives: the effects of steric hindrance in organotin chemistry. Inorg. Chem. 1966, 5, 87-91.

Shang, X.; Meng, X.; Alegria, E. C. B. A.; Li, Q.; Guedes Da Silva, M. F. C.; Kuznetsov, M. L.; Pombeiro, A. J. L. Syntheses, molecular structures, electrochemical behavior, theoretical study, and antitumor activities of organotin complexes containing 1-(4-chlorophenyl)-1-cyclopentanecarboxylato ligands. Inorg. Chem. 2011, 50, 8158-8167.

Sheldrick, G. M. A short history of SHELX. Acta Crystallogr. 2008, A64, 112-122.

Tian, L.; Cao, H.; Wang, S.; Sun, Y.; Liu, Z. Synthesis, characterization and cytotoxic activity of tricyclohexyltin(IV) carboxylates derived from cyclic dicarboxylic anhydrides. J. Coord. Chem. 2013, 66, 624-637.

Tian, L.; Yu, H.; Zheng, X.; Liu, X. Synthesis, crystal structure and cytotoxic activity of tricyclohexyltin complexes of benzenedioxyacetic acids. Appl. Organomet. Chem. 2015, 29, 725-729.

Tiekink, E. R. T. The rich diversity in tin carboxylate structures. Trends Organomet. Chem. 1994, 1, 71-116.

Wang, X.; Liu, X.; Tian, L. Synthesis, characterization and in vitro cytotoxic activity of bis(triorganotin) 2,6-pyridinedicarboxylates. Main Group Met. Chem. 2014, 37, 143-147.

Willem, R.; Verbruggen, I.; Gielen, M.; Biesemans, M.; Mahieu, B.; Baul, T. S. B.; Tiekink, E. R. T. Correlating Mössbauer and solution- and solid-state ${ }^{117}$ Sn NMR data with X-ray diffraction structural data of triorganotin 2-[(E)-2-(2-hydroxy5-methylphenyl)-1-diazenyl]benzoates. Organometallics 1998 , $17,5758-5766$.

Xie, Q.; Zheng, J.; He, S. Synthesis of tricyclohexylstannane derivatives and analysis of their structure. Chinese J. Org. Chem. 1989, 9, 367-370.

Yao, Y.; Yang, M.; Zheng, X.; Tian, L. Synthesis, characterization, and cytotoxic activity of triphenyltin complexes of $\mathrm{N}$-(5bromosalicylidene)- $\alpha$-amino acids. Main Group Met. Chem. 2017, 40, 93-99.

Zhang, J.-H.; Zhang, R.-F.; Ma, C.-L.; Wang, S.-N.; Wei, X.-L.; Zhang, S.-L. Syntheses and structural characterization of triorganotin(IV) complexes containing pamoic acid ligand. Chinese J. Inorg. Chem. 2014, 30, 664-670.

Zhang, H.; Yu, H.; Liu, X.; Tian, L. Synthesis, structural characterization and antibacterial activity of tricyclohexyltin aryloxyacetates. Main Group Met. Chem. 2015, 38, 157-164.

Zhang, S.; Wang, W.; Liu, Q.; Zheng, X.; Tian, L. Synthesis, crystal structure and antibacterial activity of tricyclohexyltin salicylates. Main Group Met. Chem. 2016, 39, 87-92. 